\title{
Crianças, seus cérebros... e além: Reflexões em torno de uma ética feminista de pesquisa
}

\author{
Claudia Lee Williams Fonseca' (iD) 0000-0002-7761-6095 \\ 'Universidade Federal do Rio Grande do Sul, Programa de Pós-Graduação em \\ Antropologia Social, Porto Alegre, RS, Brasil. 90690-410
}

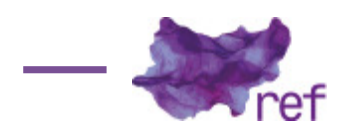

Resumo: Nesse artigo, em interlocução com autores dos estudos da ciência assim como das teorias feministas de cuidado, reflito sobre dilemas éticos associados à participação do cientista social na arena multidisciplinar das políticas públicas. Construo meu objeto de análise a partir de uma imagem que surge com frequência nos debates sobre políticas de proteção à infância que justapõe dois cérebros infantis - um etiquetado "normal", o outro, "negligência extrema". Ao rastrear, através de atores e situações concretos, a trajetória pouco ortodoxa desse artefato das neurociências, proponho reforçar uma visão crítica sobre os usos populares da ciência que tendem a ofuscar os juízes de valor implícitos em qualquer fato científico. Por outro lado, num exercício autorreflexivo, procuro entender como o "importar-se" da pesquisadora, nas suas diversas manifestações, tem implicações para o devir ético e político dos mundos sob consideração.

Palavras-chave: ética feminista de pesquisa; cuidado; desenvolvimento infantil; virada neurocientífica

Children, their brains ... and beyond: Reflections on a feminist ethic of research Abstract: In interlocution with authors from the field of science studies as well as feminist theories of care, I reflect on the ethical dilemma associated with the participation of social scientists in the multidisciplinary arena of public policy. I build my analysis around an image frequently found in debates on child-protection policy that juxtaposes two infantile brains, one labeled "normal", and the other, "extreme neglect". Upon tracing the unorthodox trajectory of this neuroscientific artefact through concrete actors and situations, I propose to reinforce a critical perspective of popularized forms of science that tend to ignore the value judgments implicit in any "scientific fact". On the other hand, in a self-reflexive exercise, I seek to understand how the researcher's "caring", in its diverse manifestations, carries implications for the ethical and political becoming of the worlds under consideration.

Key-words: Feminist research ethics; Care; Child development; Neuroscientific turn

\section{Um desconforto}

No final de setembro de 2016, participei de um congresso internacional organizado pelos Serviços da Juventude do México, que visava dar subsídios à reestruturação das leis do país em matéria de adoção de crianças. O evento contou com a participação de cerca de 300 pessoas - principalmente especialistas de vários ramos do direito, mas também havia uma série de psicólogos, alguns trabalhadores sociais e um cientista social: eu. Foi-me pedido que apresentasse minha pesquisa sobre as dinâmicas de parentesco de famílias atingidas pela pobreza no Brasil, algumas das quais tinham visto seus filhos retirados pelo poder público, abrigados e dados em adoção. Após minha fala, não houve mais menção das famílias originais das crianças adotadas. Os vários especialistas que me seguiram apresentaram material das áreas de direito e da psicologia sobre crianças adotadas e suas novas famílias. Entre as diversas contribuições, um elemento despertou minha curiosidade: a projeção de certa imagem na tela do auditório. Evocando as 
descobertas da neurociência, a imagem coloca lado a lado as silhuetas de dois cérebros, ambos (o título do slide nos informa) de crianças de três anos de idade - um etiquetado "normal", o outro "negligência extrema". Pela justaposição, ressalta-se o tamanho claramente diminuído de um dos cérebros, o da criança negligenciada.

A repetição dessa imagem em palestras sucessivas foi impressionante. Apareceu primeiro entre os slides de uma profissional peruana do direito, acompanhando sua fala sobre a capacitação de pais adotivos. Foi projetada mais uma vez por uma psicóloga espanhola que buscava descrever as consequências neurológicas do abandono e abuso infantis. Finalmente, um psicólogo chileno mostrou a imagem para ilustrar sua fala sobre a intervenção terapêutica pré-adotiva com crianças institucionalizadas. Em caso atrás caso, o slide foi projetado para sublinhar a "evidência científica irrefutável" quanto ao dano "irreversível" causado aos cérebros de crianças vivendo em circunstâncias adversas, e a necessidade imperativa de evitar tais estragos. A ideia parecia ser que as crianças que entram na categoria de "adotáveis" - tendo sido sujeitas aos traumas de abuso, negligência e abandono, tanto em suas casas originais quanto em instituições - correm sério risco de ter um cérebro permanentemente atrofiado. Assim, haveria extrema urgência para algum tipo de intervenção.

A projeção repetida da imagem despertou em mim um profundo incômodo, desencadeando uma série de dúvidas. Já estranhava o uso descontextualizado da imagem - o fato de que ninguém perguntava de onde ela vinha, com que tecnologia tinha sido constituída, a partir de uma pesquisa em quantas e quais crianças, tendo sofrido que tipo de abuso etc. Lembrei do trabalho do antropólogo Joseph Dumit (2004), que chama atenção ao uso banalizado desse tipo de artefato visual, particularmente na mídia popular. O par de imagens colocadas lado a lado, representando as realidades contrastadas de um antes e depois (ou aqui e acolá), tem repetidamente demonstrado seu enorme poder persuasivo. Não importa sua conexão lógica aos fatos sendo comunicados. Essa técnica visual de convencimento já foi usada para legitimar verdades sedimentadas do senso comum sobre praticamente tudo - a depressão, abuso de drogas, negligência infantil (ver também Sarah RIJCKE; Anne BEAULIEU, 2007).

Já havia lido sobre a "virada neurocientífica" (Melissa LITTLEFIELD; Jenell JOHNSON, 2012; Ricardo LUGON; Claudia Rodrigues FREITAS, 2016) e como o encanto popular com as promessas da ciência, alimentado em grande medida por esse tipo de imagem, tinha se deslocado durante os anos 1990 do gene para o cérebro (Joelle ABI-RACHED; Nikolas ROSE, 2010; Rogerio Lopes AZIZE, 2010). Mas, para mim, essa imagem em particular condensava o que havia de mais inquietante do novo panorama. Devido ao meu recente envolvimento na antropologia da ciência, sabia que a imagem projetada no congresso tinha uma biografia pouco ortodoxa. Apareceu pela primeira vez num poster apresentado na Reunião Anual da Sociedade de Neurociências (Nova Orleans) em 1997. Embora tenha se tornado ícone popular em debates sobre políticas para a infância no mundo inteiro, nunca foi claramente explicada pelos autores; tampouco chegou a ser publicada numa revista médica de prestígio. Sua fama é graças à internet, onde, disponível no site de um dos autores do poster, a imagem tem "viralizado" milhões de vezes (mais detalhes abaixo).

Fiquei perplexa diante da maneira como esse artefato de uma ciência popular tinha se tornado recurso central de uma discussão sobre a adoção de crianças. Procurando ir além da simples indignação entrei num processo de autorreflexão que envolvia perguntas éticas fundamentais. Como devia me manifestar naquele contexto de debate com os outros participantes do congresso? Qual seria meu dever ético de pesquisador? Devia levantar para publicamente chamar atenção ao que me parecia a falta de relevância da imagem e o caráter duvidoso de sua presença naquele contexto? Ou devia - por enquanto - permanecer calada, procurando entender o que aquela imagem podia me ensinar sobre o lugar de meus próprios conhecimentos dentro da polifonia do debate multidisciplinar? Enfim, como que eu podia usar essa oportunidade para melhor definir meu posicionamento como cientista social no cenário das políticas públicas?

Nesse artigo, pondero essas perguntas a partir de uma abordagem construída em interlocução com certos autores dos estudos da ciência e, em particular, com a proposta de Maria Puig Bellacasa (2011) para uma teoria feminista de cuidado. Esta, em diálogo com outros pesquisadores da ciência e tecnologia tais como Bruno Latour (2005) e Donna Haraway (1997), propõe levar a noção de "cuidado" além do senso comum - para longe das conotações cotidianas centradas em atitudes bondosas - para focar no seu papel na produção de conhecimentos. ${ }^{1}$ Lembrando que o termo em inglês, "care", aparece não só como verbo transitivo (cuidar de uma pessoa, de um animal, etc.), mas também, como verbo intransitivo - como estado de espírito, um tipo de importar-se ou engajar-se em determinado assunto - Bellacasa reivindica uma explicitação do engajamento afetivo do pesquisador no seu objeto de análise. Insiste que esse "importar-se" tem implicações que se estendem aos efeitos de nossas pesquisas para os mundos sob consideração:

' Encontra-se uma discussão mais detalhada sobre a abordagem analítica do "cuidado" em Helena Hirata e Nadya Araujo (2012) e llze Zirbel (2016). 
Exibir as preocupações emaranhadas no coração das coisas aumenta a percepção afetiva dos mundos e vidas que estudamos, indo além de cartografias de interesses e envolvimentos práticos. Nesse sentido, enquadrar um fato ou uma montagem sócio-técnica como matéria de care é intervir no seu devir ético e político. (BELLACASA, 2011, p. 89)²

Uma análise "cuidadosa" levaria em consideração as preocupações diversas operando na situação sob estudo, e colocaria a pergunta: como que nosso engajamento afeta a composição das coisas?

Nos parágrafos a seguir, proponho estudar essa imagem "dos cérebros-nozes"3 como objeto da tecnociência imbricado na vida real - o que me obriga a rastrear sua trajetória através de atores e situações concretos. Mas, vendo os diversos engajamentos afetivos como parte integrante da "re-presentação" desse objeto, também tomo como alvo minha própria perspectiva analítica. Assim, na procura por uma prática ética diante de dilemas como esse que vivi no México, proponho um exercício autorreflexivo que trilhe o caminho das perguntas: por que eu me importo, quem (além de mim) se importa e, em particular, como cada um de nós importamos.

\section{Historiando a imagem}

Para explicar melhor meu incômodo, seria interessante rastrear a trajetória surpreendente dessa imagem, mostrada tantas vezes por pessoas de tantos países diferentes, durante os últimos vinte anos. Sua versão original (no pôster de 1997) era para ilustrar um curto paper cujas evidências principais dependiam de medidas corporais de crianças: altura, peso e "FOC" (a medição da circunferência frontal-occipital do crânio). Tratava-se do resumo de uma pesquisa realizada por dois especialistas em psiquiatria infantil, Bruce Perry e Ronnie Pollard, que ensaiavam a possibilidade de transpor resultados de pesquisa em neurodesenvolvimento animal para seres humanos (PERRY; POLLARD, 1997). O universo empírico dessa pesquisa incluía 122 crianças, de 017 anos de idade, que chegaram em determinada clínica especializada por indicação dos serviços sociais locais. ${ }^{4}$

A base da leitura de relatos elaborados por trabalhadores sociais e psicólogos, Perry e Pollard classificaram as crianças em duas grandes categorias. Havia, por um lado, vítimas de "negligência global" - aquelas que tinham sofrido "severa privação sensorial" nas áreas de tato, linguagem e nutrição ("algumas crianças foram literalmente criadas em gaiolas, em quartos escuros, durante os primeiros anos de vida"). Por outro lado, havia as vítimas de "negligência caótica" - crianças em cujo dossiê constava alguma história consistente com negligência física, emocional, social ou cognitiva. Quando comparadas com crianças "normais", as crianças na primeira categoria - as globalmente negligenciadas - demonstraram crânios menores e neuroimagens alteradas. Os autores são claros, porém, quanto ao fato de que crianças tendo sofrido "negligência caótica" ("muito mais comum") não mostravam nenhuma diferença significativa, nem na medida do crânio, nem na interpretação das neuroimagens.

Como ocorre em praticamente toda pesquisa científica, existem no trabalho de Perry e Pollard algumas limitações metodológicas. Os dados foram coletados a partir de relatos de técnicos profissionais e exames médicos realizados ao longo da história da criança - isto é, foram constituídos fora do contexto da pesquisa, possivelmente conforme critérios descritivos muito diversos. Foi possível consultar algum tipo de neuroimagem (ora CT, ora MRI) em 43 casos (dos quais 17 de negligência extrema), cuja análise foi entregue a radioneurologistas não especificados. Não se sabe nada sobre a criança cujo cérebro parece tão diminuído (se, por exemplo, sofria de outras doenças além da subnutrição e privação sensorial), nem se devemos considerar esse cérebro como representativo da categoria (foi de tamanho médio, mediano, ou menor em relação ao universo de 17?). Tampouco aprendemos de onde vem o cérebro da "criança normal" (já que a pesquisa não incluiu um grupo de controle de "crianças normais"). ${ }^{5}$ O que surpreende neste caso não é tanto a quantidade de dúvidas circundando a pesquisa original; afinal, existem lacunas e dúvidas abertas em muitas experiências científicas - fato que não desvalida necessariamente sua contribuição para o debate. O que impressiona é como a imagem dos "cérebros-nozes" passou a ser usada para evocar os danos potenciais que rondam não as vítimas de negligência global (única categoria apontada nas conclusões da pesquisa original), e, sim, aquele universo "muito mais comum" de sujeitos - as "vítimas de negligência caótica", ou seja, praticamente toda criança vivendo na grande pobreza.

\footnotetext{
${ }^{2}$ Esta, assim como as demais traduções de inglês neste artigo, foi realizada pela autora, CF.

${ }^{3}$ Etiqueta cunhada por Zoe Williams (2014).

${ }^{4}$ Embora os autores não especifiquem o nome ou local da clínica, inferimos do curriculum de Perry que estão se referindo ao Child Trauma Academy, associada ao Texas Children's Hospital, Baylor College of Medicine, Houston, Texas - um instituto reputado pela terapia, pesquisa e educação em conexão com trauma infantil.

${ }^{5}$ Analistas lembram que, até recentemente, as neuroimagens exigiam uma tecnologia considerada invasiva; portanto, não eram realizadas em crianças sem problema de saúde (John BRUER, 1999; Joseph DUMIT, 2004).
} 
Algumas das apropriações mais exageradas dessa imagem foram desmentidas pelos próprios autores do pôster. Em conversas de 2010, o MP (Membro do Parlamento) britânico, Duncan Smith, citou o trabalho de Perry e Pollard para fundamentar suas preocupações sociais. Conforme esse político do partido conservador, neurocientistas teriam identificado nos cérebros de crianças negligenciadas "sinais físicos" capazes de indicar a probabilidade de certa criança cometer crimes mais tarde na vida. Os sinais, já detectáveis a partir de dois anos e meio/três anos de idade, seriam provocados, por exemplo, em crianças que "testemunharam muito abuso" ou aquelas cujas mães tinham tido "múltiplos parceiros diferentes" (Paul LEWIS; Sarah BOSELEY, 2010). A falta de precisão quanto à noção de "testemunhar abuso" ou a presença potencial de "múltiplos parceiros diferentes" também em famílias abastadas não parecem perturbar a lógica de quem procura lastros biológicos para justificar a associação naturalizada entre responsabilidade parental, pobreza e crime.

Em entrevista para The Guardian (4/9/2010), Dr. Perry expressou grande indignação diante das interpretações do MP. Dizendo que Duncan Smith tinha seriamente distorcido suas conclusões, o cientista lembrou que sua pesquisa dizia respeito a crianças que sofreram formas extremas de negligência, que tinham sido (por exemplo) "trancadas num porão sem contato humano". Insistiu que seria um equívoco aplicar seus achados a crianças tendo sofrido formas menos violentas de negligência tais como aquelas oriundas de "famílias desestruturadas". Ironicamente, apesar dessa altercação entre o cientista e o MP, pouco tempo depois outro Membro do Parlamento, Graham Allen - e coautor, com Duncan Smith, de um livro sobre o desenvolvimento infantil — publicou um "relatório independente" para o governo britânico, ostentando a imagem "cérebros-nozes" na capa (ALLEN, 2011). Entre muitas descrições sobre neurónios e o cérebro infantil, o volume dá destaque a uma pesquisa que sugere como, já com três anos de idade, certas crianças "em situação de risco" são destinadas a um futuro de violência criminal.

A bem da verdade, não é surpreendente a imagem ser usada para sugerir problemas em crianças pobres em geral. O próprio Perry parece vacilar quanto à relevância de seus dados para crianças "tendo sofrido negligência menos severa". Apesar da pesquisa de Perry e Pollard não apresentar nenhuma evidência quanto a alterações cerebrais em crianças vítimas de "negligência caótica", o texto do pôster começa com menção das 500.000 crianças que passam todo ano pelo serviço de proteção à infância nos USA - crianças que, conforme os autores, teriam grande probabilidade de ter atrasos ou disfunções emocionais, comportamentais, cognitivos, sociais e físicos. E o pôster termina com uma frase quase esperançosa de futuramente poder constatar problemas cerebrais numa população ampla de vítimas: "Enquanto o tamanho dos cérebros entre crianças caoticamente negligenciadas não parece ser diferente da norma, é razoável pressupor que anomalias organizacionais existem" (PERRY; POLLARD, 1997).

O problema é que não fica nada claro qual infância e qual família seriam necessárias para evitar as "anomalias organizacionais" do cérebro infantil. Em 2002, num longo ensaio sobre a "infância e a expressão de potencial genético", ‘ discorrendo sobre a história da humanidade (ainda que sem referências bibliográficas), Perry dá algumas pistas:

Nosso cérebro evoluiu ao longo de centenas de milhares de gerações em grupos sociais hominídeos e pré-hominídeos. Nessas pequenas bandas de caçadores e coletores, um complexo e dinâmico ambiente socioemocional proporcionava experiências para o "desenvolvimento da criança". Em um grupo de cinquenta pessoas, existiam três ou mais adultos para cuidar de cada criança menor de seis anos. E havia pouca privacidade. Uma criança dependente crescia na presença de idosos, irmãos, adultos - aparentados ou não. Tinha uma exposição mais contínua e com maior variedade de "interações socioemocionais". A criança nessa situação tinha muitas oportunidades [...] para desenvolver a capacidade de ter uma grande variedade de relacionamentos. (PERRY, 2002, p.96)

Dr. Perry sugere que é nessas comunidades de laços estreitos que as crianças se desenvolviam bem - muito melhor do que no "mundo moderno compartimentalizado". Há certa ironia no fato de que esse tipo de família extensa não é ao todo incomum em bairros pobres do mundo contemporâneo onde - entre as várias avós, tias, madrinhas e mães - as crianças podem crescer entre cuidadoras múltiplas (Claudia FONSECA,1995). Contudo, Perry parece afastar a possiblidade de assemelhar o modelo que idealiza (entre caçadores-coletores) a exemplos concretos do mundo contemporâneo. Assim, a imagem que produziu em 1997 segue sendo usada mundo afora para sugerir os efeitos nefastos para o desenvolvimento infantil de qualquer contexto familiar que desvia da família conjugal nuclear idealizada das camadas médias.

Um recente exemplo de tal uso apareceu em outubro de 2012, no Medical Daily (um produto on-line da rede Newsweek). No artigo ilustrado pela imagem de Perry e Pollard, não só a pesquisa desses autores (já velha, de 15 anos) é apresentada como evidência "nova" e "chocante" sobre ameaças ao desenvolvimento do cérebro infantil, mas destaca-se o papel central do "amor materno" - elemento que nem sequer foi mencionado na pesquisa de 1997: 'É nesse artigo que a imagem de Perry e Pollard, ainda sem detalhes contextuais, veio a ser publicada numa revista
acadêmica (de baixo impacto). 
Os neurologistas [Bruce D. Perry, M.D., Ph.D.] dizem que a diferença considerável entre esses cérebros de duas crianças diferentes tem uma causa principal: a maneira como as mães trataram seus filhos. (Christine HSU, 2012, p.1)

Em suma, vemos como as conclusões originais da pesquisa foram esquecidas atrás das várias apropriações de uma imagem que consta quase como um post-scriptum no pôster original. Os danos cerebrais que, no texto original, eram claramente restritos a crianças que sofreram negligência global, incluindo severa privação sensorial, acabam se estendendo a crianças que "testemunharam muito abuso", cujas mães tiveram múltiplos parceiros ou que, simplesmente, não receberam amor materno suficiente. Parece que estamos diante de um fenômeno tão expressivo (a imagem) que preocupações com as "evidências científicas" somem atrás da possibilidade de reforçar ideias preconcebidas do senso comum.

\section{Respeito pela complexidade}

Para resolver como devia me conduzir quando confrontada com o uso repetido da famosa imagem durante o congresso no México, precisava responder à pergunta: por que eu tinha uma reação tão forte diante de uma imagem que as centenas de pessoas na plateia pareciam aceitar como algo evidente, esclarecedor e útil? Por que eu via aquela imagem como influência negativa sobre as políticas públicas de infância?

Minhas inquietações tinham certamente a ver com duas décadas de experiência em pesquisas etnográficas entre famílias em bairros das classes trabalhadoras de Porto Alegre (Rio Grande do Sul, Brasil). Esta experiência me colocou em contato direto com pessoas de condições muito modestas, cujas crianças pequenas podiam ser removidas por trabalhadores sociais, enviadas para instituições ou doadas em adoção, e cujos filhos adolescentes podiam ser condenados pelos tribunais a passar longas temporadas numa instituição de correção. Cheguei a conhecer a discriminação esmagadora que pesava sobre essas pessoas, e - em muitos casos - vim a apreciar a impressionante criatividade que famílias e comunidades exerciam para lidar com as desvantagens sociais e estruturais que experimentavam no seu dia-a-dia (FONSECA, 1995, 2000).

Por causa desses anos de pesquisa etnográfica, eu e os membros da minha equipe acabamos fazendo consultorias episódicas com administradores nas instituições que acolhiam crianças e adolescentes - o que proporcionava a possiblidade de pesquisa nos diferentes elos da rede de atendimento (FONSECA; Patrice SCHUCH, 2009). Chegamos a reconhecer que existem situações problemáticas que exigem a retirada de crianças de suas famílias originais e a colocação em lar substituto. Descobrimos que tem uma grande variedade de formas de acolhimento, algumas mais interessantes, outras menos. A nossa tarefa passou a ser destacar aquelas modalidades que pareciam melhor tecer uma conexão entre os interesses da criança e as circunstâncias particulares de sua trajetória - modalidades que incluíam "famílias acolhedoras" (conveniadas ou informais), acolhimento entre membros da família estendida, e mesmo abrigos de pequeno porte. Em muitos casos, os serviços de atendimento conseguiam preservar a identidade original da criança, garantindo a manutenção de vínculos entre irmãos, com avós e outros parentes, e até com os próprios pais (José Carlos Sturza de MORAES, 2012; FONSECA; SCHUCH, 2009; Fernanda Neísa MARIANO; Maria Clotilde ROSSETTI-FERREIRA, 2008; Janete VALENTE, 2013). Tratava-se de programas financeiramente onerosos e frequentemente de complicada administração (exigindo grandes investimentos profissionais), mas que representavam alternativas que pareciam funcionar razoavelmente bem em termos do interesse das crianças tanto quanto da justiça social.

Esta experiência dentro da própria rede de atendimento me convenceu, mesmo antes de me aprofundar na literatura de Estudos da Ciência e Tecnologia (ECT) e na teoria feminista do cuidado, de que os problemas que enfrentavam famílias, crianças e profissionais do campo da infância não eram nada simples. A complexa interação das realidades políticas, econômicas, médicas, emocionais e institucionais exigia uma atenção aos detalhes específicos de cada caso. O desafio para os gestores públicos, tal como eu o entendia, era evitar perspectivas reducionistas que explicassem a pobreza das famílias, o sofrimento dos jovens institucionalizados, ou mesmo a violência que assolava a sociedade, em termos de uma "causa final" - seja de natureza política ou socioeconômica, seja de natureza psicossocial ou familiar. Dada a complexidade das situações, a heterogeneidade da rede de atendimento e a variabilidade de condições concretas de cada família, me parecia fundamental garantir um debate aberto sobre as possíveis formas de intervenção. O problema de qualquer reducionismo é que tende a fechar o debate, editando no seu lugar receitas mágicas - fórmulas prescritivas a serem aplicadas em todos os casos.

Ao longo dos anos 1980 e 1990, o reducionismo que eu encontrava com maior frequência entre analistas e profissionais do campo da infância vinha de certa psicologia normativa - a que localizava a causa de "comportamentos desviantes" nas famílias "desestruturadas", nos pais ausentes ou maltratantes e na maternagem inadequada. Contudo, com a virada do século, outra ciência estava rapidamente se tornando autoridade em questões de bem-estar juvenil: uma 
forma particular e popularizada de neurociências. As explicações biomédicas sobre o comportamento "desviante" de crianças pobres não eram realmente novas. Durante minhas pesquisas de campo nos anos 80 , não era incomum ouvir algum professor ou mesmo diretor de escola primária justificar o fracasso de seus alunos em termos de "lesões cerebrais" generalizadas (ver também Dorith SCHNEIDER, 1985). Agora, vinte anos depois, esses discursos estavam voltando em peso, tendo encontrado uma expressão visual nas cada vez mais difundidas tecnologias que permitiam "ver" o cérebro (ver LUGON; FREITAS, 2016).

Hoje em dia, em nossa "sociedade do risco", mais do que nunca, as atenções parecem se concentrar no "diagnóstico precoce" de sinais sutis de desvio orientado para a prevenção de problemas físicos e psicossociais (Helena MACHADO, 2015; ROSE, 2010). Não é surpreendente que a ciência do momento - a neurociência - encontre um lugar importante nessas preocupações preventivas. Mas, a facilidade de traduções visuais desse ramo da ciência propicia uma enorme popularização, acompanhada por uma igualmente enorme possibilidade de operar ressignificações pouco ortodoxas. Em 2007, por exemplo, um dos programas mais populares da televisão brasileira conseguiu encantar espectadores, projetando na tela uma imagem multicolorida do cérebro. Essa evocava a pesquisa a ser realizada nos cérebros de "adolescente infratores" por determinado médico-geneticista à procura das "origens do comportamento criminal" (ver FONSECA, 2010). Na reportagem não havia menção das muitas controvérsias (inclusive entre neurocientistas) que circundam esse tipo de pesquisa, nem ao fato de que a pesquisa estava na fase embrionária (de fato, nunca chegou a ser realizada). Mas podemos imaginar que a reportagem ajudou a firmar, no imaginário público, a ideia de que a criminalidade se explica em grande medida por anomalias biológicas do cérebro.

Além dessa "neurociência moral" que procura a razão de comportamentos antissociais na biologia de um indivíduo (ver Stephan SCHLEIM, 2014), existe um ramo da neurociência que postula uma associação entre o estimulo precoce do cérebro e a performance cognitiva - ou seja, a inteligência - na vida adulta. Não é, ao todo, surpreendente de que, uma vez traduzida via artigos na mídia popular, essa linha de investigação parece afirmar que o "estímulo precoce" mais benéfico é justamente aquele que mais parece com as práticas da cultura da elite. Um caso desse tipo de retradução diz respeito ao "efeito Mozart", i.e., a ideia de que a escuta de música clássica melhora a performance intelectual das pessoas. A pesquisa norte-americana original, que descrevia um estudo com estudantes universitários durante seus exames no final de semestre, acaba sendo apresentada na mídia como se dissesse respeito, antes de tudo, ao desenvolvimento cerebral de recém-nascidos. E chegando até as políticas públicas de um dos estados mais pobres dos USA, essa compreensão fantasiosa da pesquisa científica teve como resultado o gasto com CDs de música clássica a serem distribuídos para todo recém-nascido [Cliodhna O'CONNOR; Geraint REES; Helene JOFFE, 2012; O'CONNOR; JOFFE, 2013; Tineke BROER; Martyn PICKERSGILL, 2015].

Adentrando as políticas públicas no Brasil, a prioridade atribuída às "evidências neurocientíficas" subscreveu as observações de certo grupo de especialistas (oriundos, além das diferentes áreas médicas, da matemática e da economia) comissionado pela Academia Brasileira de Ciências para elaborar um documento sobre a Educação Infantil. Nas conclusões de seu relatório final, dizendo se pautar na "neurobiologia da aprendizagem", os autores sublinharam a urgência de uma política de estímulo cerebral na primeira infância justamente para aprimorar:

o desenvolvimento cognitivo que é precário em boa parte das famílias brasileiras, principalmente aquelas provenientes de famílias de baixa condição socioeconômica. (ABC, 2009, p.2)

O relatório não explicita os critérios usados para definir "desenvolvimento cognitivo precário", nem cita pesquisas para mostrar uma comparação sistemática entre os diferentes setores da população brasileira. Num raciocínio circular, o êxito escolar e acesso a emprego - dois fatores estreitamente associados à condição de classe - servem implicitamente como medida.

Ora, minha formação profissional me leva a abordar com cautela discursos que vinculam a biologia de certa classe, população ou raça a habilidades cognitivas e disposições comportamentais. Repetidas pesquisas têm demonstrado que as "evidências científicas" que pretendem mostrar tal associação não apenas são altamente controvertidas, mas, quando apropriadas por gestores políticos, se prestam a políticas discriminatórias (Alexandra STERN, 2005). Analistas nos alertam quanto às proximidades inquietantes entre as vertentes populares da ciência e perspectivas lombrosianas do início de século XX. A aparente finalidade dos vereditos arraigados no corpo - que se refiram a atributos inatos (genéticos) ou adquiridos (de desenvolvimento) estaria alimentando noções sobre a inferioridade (moral, intelectual, civilizatória...) de determinadas pessoas, senão de populações inteiras (ver MACHADO, 2015; ROSE, 2013).

No seu recente livro Neuro, Nikolas Rose resume algo dessas inquietações. Sugere que o reducionismo neurobiológico apoiado em imagens como essa dos "cérebros-nozes" reflete um certo estilo de pensamento visto "inúmeras vezes desde o século dezenove" em que a violência e a injustiça aparecem como resultado de falhas de caráter em certos indivíduos. Esse tipo de explicação omite por inteiro considerações estruturais de desigualdade e discriminação. A exclusão 
social e econômica persistente de certos setores da sociedade seria causada, antes de tudo, por um ciclo repetido de pais inadequados e filhos mal-amados (ROSE, 2013, p.16; ver também BRUER, 1999).

Justamente graças ao seu poder comunicativo, esse tipo de imagem é seletivamente apropriado e reinterpretado - pela imprensa tanto quanto por gestores públicos - não para questionar ideias preconcebidas, mas para reforçar preconceitos antigos. Uma suposta legitimidade científica vem apoiar a ideia de que o bom desenvolvimento das crianças - e, por extensão, da nação - depende da realização de um modelo idealizado de família classe média (ou alta) em que as mulheres se dedicam integralmente às suas responsabilidades maternas. Nesse quadro, as famílias de baixa renda (e, em particular, as mulheres que, nem se quisessem, não teriam tempo ou recursos para realizar o modelo idealizado) são por definição vetores potenciais do desenvolvimento inadequado.

Aplicado às políticas de "proteção à infância", esse raciocínio tem implicações problemáticas. Se, por exemplo, imaginamos que as famílias pobres produzem crianças com danos cerebrais, é preciso uma política rápida e radical para prevenir nesses jovens estragos neurológicos irreversíveis. A solução "óbvia" do problema seria a agilização da adoção de crianças pobres - em particular bebês - por famílias das classes medias e altas. Trata-se de uma perspectiva abraçada por muitos pais adotivos em potencial, frustrados diante do que lhes parecem procedimentos demorados nos Juizados, que resultam em longas demoras antes da realização de uma adoção. Por outro lado, do ponto de vista de alguém que não crê na associação entre pobreza e dano cerebral, a cautela dos Juizados de Infância - a insistência destes em conduzir adoções de forma cuidadosa - é plenamente justificada. Existem questões de identidade familiar e convivência comunitária a serem contempladas no interesse da criança, além das considerações sobre responsabilidade pública e justiça social. São quase sempre situações complexas, que desafiam os raciocínios reducionistas. Antes de tudo, são situações que, não apontando para nenhuma solução "óbvia", exigem tempo para a consideração das diversas soluções possíveis.

\section{A divergência de perspectivas}

É evidente que não sou a única pessoa a me importar com essas questões. Não é exagero dizer que existe uma multidão de profissionais e cientistas que, mais do que se interessarem pelo tema do desenvolvimento infantil, se importam com paixão e estão constantemente em busca de medidas para contribuir a reflexões e políticas sobre esse tema. Em certo sentido, é possível falar de "consenso" quanto a princípios básicos do desenvolvimento infantil: crianças tendem a se desenvolver melhor em ambientes seguros onde podem interagir com outras crianças e adultos carinhosos; a extrema pobreza, via de regra, não faz bem à saúde e pode dificultar a aprendizagem de comportamentos sociais e capacidades emocionais adequados a certos papeis adultos. Ainda mais, a maioria de analistas contemporâneos - que venham das ciências "exatas", humanas ou comportamentalistas - não colocaria o "biológico" aquém dos processos complexos que "coproduzem" qualquer indivíduo (Sheila JASANOFF, 2004). Mas há profundas divergências quanto à maneira em que as atuais "evidências" neurocientíficas, produzidas a partir de um fragmento corporal - o cérebro - se traduzem para habilidades cognitivas e manifestações comportamentais. Assim, as paixões investidas na questão de desenvolvimento infantil nem sempre convergem para os mesmos diagnósticos ou soluções.

Em outro lugar, formulei as divergências em termos de dois "estilos de raciocínio" que passo a resumir brevemente aqui (FONSECA, 2012). Num primeiro estilo, existem especialistas, em particular homens de diferentes áreas médicas (neurologia, psiquiatria), que veem o desenvolvimento infantil em termos da estimulação cerebral especialmente na primeira infância. Insistindo na noção de "janelas de oportunidade", o documento canônico dessa linha de "Early Childhood Development" (ECD) afirma que: "Os efeitos da experiência precoce (especialmente durante os primeiros três anos) sobre os circuitos dos bilhões de neurónios do cérebro, dura a vida inteira" (Margaret MCCAIN; Fraser MUSTARD, 1999, p.7). Junto com a sensação de urgência (é preciso agir antes que seja tarde demais), sublinha-se a relativa ineficácia de programas educacionais para crianças mais velhas, adolescentes e adultos, onde "o retorno" do investimento nacional seria "nulo ou muitas vezes negativo (custo maior do que o benefício)" (ABC, 2009, p. 2). A mãe seria a pessoa natural a prover os cuidados adequados ao desenvolvimento do bebê, sendo creches e pré-escolas substitutos arriscados: os achados da neurociência dariam aval "ao que a boa maternidade (mothering) tem feito durante séculos " (MCCAIN; MUSTARD, 1999, p.6). Entretanto, certas mães (geralmente, as mais pobres) carecem das habilidades necessárias, e, portanto, exigem uma orientação pedagógica especial para lhes ensinar a proporcionar estímulos adequados ao seu rebento.

Desde que esse estilo de raciocínio foi abraçado pelo Banco Mundial, proliferam no mundo programas que consistem em visitas a domicílio por monitoras que supervisionam a relação mãefilhos (Mary Eming YOUNG, 2007). O primeiro programa no Brasil iniciou no Rio Grande do Sul em 2003, à iniciativa do então secretário estadual de saúde. Por visitas periódicas ao domicílio da 
mãe, monitoras (com segundo grau completo) deviam ensinar "gestos simples como acariciar a barriga da gestante durante a gravidez, olhar o bebê nos olhos e brincar com a criança", oferecendo conselhos e alguns materiais (fraldas, roupas, joguinhos). ${ }^{7}$ Dessa maneira, o programa garantiria às crianças o bom aproveitamento das "janelas de oportunidade" do desenvolvimento cerebral. Com a mudança de governo no RS, esse programa passou por um momento de recuo, mas, em 2016, com a nomeação do médico incentivador como Ministro de Desenvolvimento Social, voltou a ser promovido, essa vez em escala nacional.

Representando um estilo distinto de raciocínio, pesquisadoras das ciências humanas (psicólogas, sociólogas, educadoras), na sua maioria mulheres, citam farta pesquisa para arguir que o bom desenvolvimento das crianças depende, antes de tudo, da expansão da rede e do aprimoramento da qualidade de creches e pré-escolas. Conforme essa linha de raciocínio: em muitas famílias, literalmente todos os adultos são obrigados a se engajar em empregos extra domésticos, realizando trabalho remunerado "fora de casa" para garantir as necessidades básicas do grupo doméstico. Nesses casos, o cuidado das crianças menores se apresenta como um constante desafio e as alternativas acionadas - dependendo do apoio de compadres, da família extensa ou dos serviços pagos de algum vizinho - são de resultado muito variável (ver Camila FERNANDES, 2017). A disponibilidade de creches e pré-escolas bem equipadas e com profissionais qualificados atenciosos, geograficamente e financeiramente acessíveis a todas as famílias, seria a política pública indicada para garantir a toda criança as condições básicas para um bom desenvolvimento. Reivindicando maiores investimentos públicos para essa área, analistas brasileiros sublinham o fato de que, em 2012, com apenas $21 \%$ das crianças de 0 a 3 anos inscritas numa creche ou pré-escola, Brasil estava no antepenúltimo ranking para educação infantil entre os 36 parceiros do OCDE (IBGE, 2013). E lembrando que quanto mais alta a renda familiar, mais as chances de a criança frequentar uma creche, apontam para a desigualdade inerente no atual sistema:

A baixa oferta de creches públicas se torna mais grave pelo fato de afetar predominantemente as crianças de mães trabalhadoras, das famílias de renda mais baixa. Inúmeros problemas de saúde, desnutrição, violência, abandono, restrições ao desenvolvimento e aprendizagem poderiam ser evitados se as famílias pudessem contar com serviços públicos de qualidade, em centros de saúde, centros de assistência social e estabelecimentos de educação infantil, além de políticas de segurança, saneamento, lazer e apoio à organização comunitária em suas áreas de residência. (Vital DIDONET, 2010, p.19)

É evidente que as implicações políticas desses dois estilos de raciocínio apontam para soluções bem diferentes. Para os adeptos da primeira linha de raciocínio, o foco está no estímulo cerebral precoce - o que é melhor garantido na família, em particular por mães em dedicação integral. A responsabilidade das autoridades públicas é assessorar as mães para que melhor cumpram seu papel natural. Para os adeptos da segunda linha, é urgente uma política pública que garante acesso a creches, pré-escolas e outros serviços públicos de qualidade para atender à grande demanda - especialmente para aquelas famílias que não têm como pagar um estabelecimento privado.

Não há nada estranho que existam perspectivas diversas entre cientistas, conforme seus respectivos instrumentos e abordagens analíticos, quanto ao diagnóstico de problemas sociais e recomendações para intervenção. Contudo, nesse caso, o que nos impressiona é como a primeira linha de raciocínio ganha rapidamente ascendência nos debates políticos graças ao seu apelo às "evidências da [neuro]ciência". Não importa que as experiências que produziram essas evidências sejam muitas vezes a base de universos empíricos tão pequenos, que qualquer generalização fica duvidosa; não importa que as controvérsias entre neurocientistas são tamanhas, que eles mesmos se acusam de produzir dados e imagens completamente "sem significância" (DUMIT, 2003); não importa que a reação contra as extrapolações abusivas das neurociências já tenham gerado um "manifesto" assinado por dúzias de especialistas internacionais alertando contra "o uso oportunista de pesquisa científica [em neurociências] para racionalizar políticas pré-concebidas e noções populares" (Santiago Declaration, 2009). No campo interdisciplinar da infância, a evocação (especialmente imagética) do cérebro parece anunciar a verdade última. Nesse caso, vem a calhar o alerta de Dumit (2004) de que o brilho da neurociência arrisca ofuscar os juízes de valor implícitos nas políticas públicas, fazendo com que os valores de um determinado grupo adquiram o valor de fato científico.

\section{Plateias plurais}

Voltando à minha experiência no congresso mexicano, a questão persiste: como entrar no debate com esses profissionais e gestores públicos quando meus relatos etnográficos, vistos por muitos da plateia como "anedotas" (isto é, de relevância limitada), são ofuscados pelas verdades

7 "Primeira Infância Melhor completa um ano e já atende 4 mil famílias". Estado do Rio Grande do Sul — Notícias, 6/ 6/2004, no site http://www.estado.rs.gov.br/. 
aparentemente universais transmitidas pelos cérebros-nozes? Naquele momento, meu desconforto vinha não só do fato de que estava longe do aconchego do mundo acadêmico e os consensos disciplinares (em que, antes de qualquer um abrir a boca, parece que já nos entendemos). Meu desconforto vinha de uma inquietação ética: para que tanto dinheiro e esforço investidos na pesquisa "básica" (nas ciências sociais) se esta não encontra traduções produtivas para fora das bibliotecas universitárias? Se nossa contribuição fica como mero enfeite nos debates "duros" das tecnologias de governo?

Talvez, o primeiro passo para enfrentar essas questões é lembrar que minha "plateia" era, ela mesma, diversa. Assim, antes de pensá-la como um bloco homogêneo abstrato, será que eu não deveria refletir mais sobre as pessoas presentes no congresso mexicano? Olhando melhor, tinha que admitir que, entre o administrador de empresas recém-chegado de uma carreira com firmas multinacionais, a militante de direitos humanos especializada em violência doméstica, a trabalhadora social que gerencia um programa de famílias acolhedoras e o psicólogo que oferece sua clínica particular para assessorar famílias adotivas, havia enormes diferenças. Vinham de países diversos, com leis e políticas distintas. Algumas dessas pessoas tinham décadas de experiência no trabalho prático, diretamente com crianças e famílias em situações problemáticas. Outras ocupavam cargos políticos, significando um engajamento mais delimitado no tempo, mas não necessariamente menos intenso. Com raras exceções, as pessoas tinham vivido experiências concretas, trazendo avaliações ponderadas sobre os diferentes programas e propostas ligados à adoção de crianças. O ambiente escolhido para o evento - um hotel-spa, à beira-mar - propiciava espaços de conversa informal onde podíamos conhecer melhor com quem estávamos dialogando. Foi nessa troca de experiências, fora do programa formal do evento, onde, além de ter um feedback produtivo sobre alguns temas da minha palestra, comecei a apreciar a riqueza de conhecimentos congregados nesse evento.

Corolário ao reconhecimento da natureza heterogênea do universo de meus interlocutores naquele local, retenho a ideia sublinhada pelos estudos sociais da ciência (LATOUR, 2005) da natureza aberta, indeterminada dos processos. Ao meu ver, a imagem dos cérebros-nozes carrega conotações problemáticas - racistas e classistas. Será que é essa a conotação que meus colegas estavam captando e aplaudindo com tanto entusiasmo? Será que a imagem transmite a todos uma visão biomedicalizada da pobreza, apresentando jovens criados naquelas circunstâncias como necessariamente e "irreversivelmente" danificados? Ou, lembrando os caveats que analistas proferem quanto a críticas simplistas da "biomedicalização" (Dominique BEHAGUE, 2015), será que não devo atentar mais para os significados locais e heterógenos acionados no uso concreto dos saberes e artefatos médicos? Vista como "mediador" latouriano, a imagem não poderia escapar ao determinismo pessimista de minhas previsões, produzindo surpresas no caminho?

É verdade que a discussão sobre a adoção de crianças tendia a traçar uma hierarquia normativa de famílias "mais" e "menos funcionais", e as intervenções propostas visavam, antes do que a gestão de condições estruturais, o atendimento de indivíduos. A tônica, porém, era mais nos saberes psi do que nos propriamente médicos. Embora, ao projetar imagens de cérebros atrofiados, os conferencistas falavam de "dano irrevogável", esta retórica desaparecia misteriosamente à medida que adentravam as diferentes formas de terapia psicológica e comportamental que podiam garantir uma transição bem-sucedida das crianças adotadas para a vida adulta. (De fato, em três dias de conferência, não ouvi uma recomendação sequer quanto ao uso de medicamentos...) Em outras palavras, da mesma forma que os palestrantes pareciam usar a imagem do cérebro como simples "bandeira de alerta", ${ }^{8}$ sem conexão evidente com o tema da palestra, assim os ouvintes pareciam absorver essa imagem - sem que ela perturbasse os princípios, diagnósticos e recomendações que abraçavam na sua prática.

Certamente havia diferenças entre minha maneira de entender e agir sobre os problemas discutidos e a de boa parte dos participantes do congresso, mas creio que a imagem projetada na tela era de menos nessa história. Ostensivamente, a maior diferença dizia respeito à percepção das famílias de origem das crianças adotadas - implicitamente rotuladas como "negligentes" ou "abandonantes", quando não ignoradas por completo. Mas, os valores subjacentes a essas atitudes, lidando com família e classe, tinham a ver com diferenças ainda mais profundas sobre filosofias de governo. Por que os gestores da administração pública que organizavam o evento haviam selecionado convidados oriundos, na sua maioria esmagadora, das ciências do direito e da psicologia? No fundo, surge a questão da própria ciência: em que consiste uma ciência legítima, de peso... e útil? Para esses gestores, vale mais uma ciência que produz enunciados claros e contundentes (mesmo quando pouco conformes à realidade complexa) ou uma ciência cuja sofisticação lógica é tal que só os colegas acadêmicos têm a paciência de colher as frutas e imaginar aplicações práticas? Em suma, entre meus colegas no congresso e eu, as divergências

\footnotetext{
${ }^{8}$ Este uso foi explicitado recentemente por certo neurocientista dando entrevista sobre os efeitos negativos da pobreza para o cérebro. O jornalista pergunta: "Já sabíamos que a pobreza é ruim para a nossa saúde. Qual seria então a novidade?" O entrevistado reconheceu que outras abordagens já tinham mostrado problemas criados pela pobreza, mas que a abordagem dele tinha a vantagem de "chamar a atenção ao tema. As bonitas imagens do cérebro parecem ter mais impacto do que imagens de crianças famintas" (Folha de São Paulo, 5/6/2017).
} 
de perspectiva - de fundo político e epistemológico - extrapolavam em muito as disputas em torno da legitimidade da imagem dos cérebros-nozes. Essas divergências não deviam ser ignoradas, mas tampouco deviam impedir o diálogo.

\section{A pesquisa como "Matéria de cuidado"}

Inicialmente pensava que podia resolver meu dilema com uma simples pergunta: onde quero chegar nesse diálogo? Mas a resposta não era simples. Talvez a consideração mais importante para mim, naquele momento do congresso, era levar em consideração a relevância circunstancial dos meus conhecimentos. Antes de ver meus achados como "verdades absolutas", invariavelmente válidos em todas as situações, tinha que pensar sobre o estilo e linguagem de meus enunciados, lidos de forma diferente conforme minha plateia. Como professora universitária, aposto no ensino da uma ciência crítica, desestabilizadora, em que a autovigilância epistemológica nos obriga a constantemente rever a lógica de nosso próprio raciocínio e o de colegas. Mas, será que essa meta da "boa ciência" não soa pedante, senão arrogante, em outros contextos? Há tempo que antropólogos chamam atenção para a dinâmica de raciocínios "não-lineares" não só entre leigos, mas também entre membros das categorias profissionais e científicas (BEHAGUE, 2015; LATOUR, 2005). Reconhecendo essa possibilidade, meu papel não seria pensar como me locomover num cenário que comporta esses outros raciocínios (antes de simplesmente denunciá-los)?

Refletindo sobre os efeitos antiproducentes da "crítica corrosiva" típica da primeira geração de estudos sociais da ciência, Latour evoca a imagem de Zeus que, embora deus soberano, reina sobre um território deserto. A ideia é que esse deus pomposo, de tão severo, teria espantado todos os seus súditos, tornando seu governo sem sentido (LATOUR apud BELLACASA, 2011). Assim, Bellacasa, reafirmando as lições da antropologia contemporânea, deixa claro que não cabe pensar em termos de blocos opostos, um "nós" versus "eles". Tampouco se deve partir de suspeitas preconcebidas que reduzem o fazer científico a um jogo de interesses antagônicos e estratégias de poder. As perspectivas críticas continuam fundamentais, mas devem ser formuladas de forma que "mais do que simplesmente expor ou produzir conflitos, engendram relações de cuidado" (BELLACASA, 2011 , p. 97).

Latour, para chamar atenção para a natureza man-made dos fatos científicos, recorre a um jogo de palavras, substituindo a expressão "matérias de fato" (matters of fact) por "matérias de preocupação" (matters of concern). Com esse novo termo, o autor sublinha como os objetos produzidos em laboratório são o ponto de convergência de agentes e engajamentos diversos. Sugere que os "fatos objetivos" da ciência clássica, quando olhados de perto, se mostram nada inertes e, sim, dinâmicos - "visíveis, arriscados, custosos, disputáveis, interessantes e publicamente relevantes" (2005, p. 115). Bellacasa, a partir da filosofia feminista, propõe transformar "matérias de preocupação" em "matérias de cuidado" para acentuar o engajamento ético e afetivo do cientista. Na perspectiva dessa autora, enfatizar o "cuidado" na prática científica tem a ver não só com a contemplação da complexidade das questões sob estudo e a escuta atenciosa de vozes diversas, mas também com o "agir e intervir". Mais do que elaborar grandes generalizações ou procurar pistas para "desvelar" a realidade última dos fatos, é preciso perguntar como nós analistas participamos do desenrolar da realidade que pretendemos estudar.

Bellacasa insiste que seu propósito não é ceder à "armadilha epistemológica" (que, conforme vaidades acadêmicas, procura estabelecer quem tem "mais razão"), nem acrescentar novas avaliações moralistas ao campo de debate (reduzindo o fazer científico a uma disputa de interesses ou cálculos racionalistas de dominação). Não abandona uma perspectiva crítica. Reivindica uma atenção especial para práticas de cuidado realizadas por atores marginalizados - práticas facilmente deixadas sob silêncio ou desvalorizadas. E, trazendo essa ênfase para dentro dos STS, propõe investigar a maneira em que coletivos sociotécnicos podem (ou não) reforçar as relações assimétricas que desvalorizam o cuidado. Contudo, cuida, nas suas análises críticas, para não provocar uma "(des)articulação simplista do mundo" (BELLACASA, 201 1, p. 88; ver também MOL, 2008). E, para alcançar seu objetivo - contribuir para um "mundo habitável" em que se promove relações de cuidado - evoca um princípio canônico do método etnográfico: ficar "perto do chão", procurando levar em consideração toda a complexidade técnica, política e moral de situações concretas em contextos específicos.

Seguindo nessa linha, proponho retomar meu dilema no congresso mexicano, naquele espaço de busca coletiva por maneiras de fomentar o "bom cuidado" de crianças. O uso selvagem daquela imagem dos cérebros-nozes agrediu profundamente o cientista social em mim. Motivou uma investigação que me abriu para um universo de críticas probantes realizadas por colegas, em particular das ciências humanas, evocadas ao longo desse artigo. Dando vazão a minha indignação, faz sentido eu juntar minha voz à desses colegas, lutando - em nome de nosso fazer científico - por um lugar de mais impacto nas atuais tecnologias do governo. Não justifica, porém, no contexto daquele evento, eu virar ouvidos moucos a tudo que os outros palestrantes tinham para dizer. E muito menos, tentar corrigir seus "erros lógicos". 
Vejo como minha responsabilidade chamar atenção para as variadas formas de cuidado que encontrei durante minhas pesquisas etnográficas em famílias de baixa renda. Quero diminuir a certeza de gestores que crianças só chegam nos serviços de proteção porque são mal-amadas. Quero falar das muitas estratégias que as famílias e comunidades acionam para, mesmo com pouquíssimos recursos, tentar cuidar bem de suas crianças. Isto é, um dos meus objetivos é trazer para o debate e valorizar formas normalmente marginalizadas de cuidado. Para tanto, devo também analisar relações assimétricas nos debates científicos que envolvem os serviços de proteção - assimetrias que operam para ocultar ou denigrir essas formas "alternativas" de cuidado. Porém, acima de tudo, quero formular minha contribuição ao debate para que, em vez de aumentar oposições, ela age para estimular a escuta mútua necessária para a produção de intervenções "cuidadosas".

"Ficar perto do chão" diz respeito não só à condução de nossas pesquisas, mas também à reflexão sobre a divulgação de nossas conclusões. Significa perguntar quem, em determinado momento, constitui minha plateia e como meus interlocutores vão entender o que tenho para dizer (Didier FASSIN, 2013). Tudo isso para explicar que - naquele dia - fiquei calada. Fiquei quieta e escutei meus colegas durante os dias subsequentes - tanto dentro como fora dos espaços formais de fala -, e aprendi muito. Ademais, creio que minha "voz" foi escutada por alguns. Apesar disso, não posso dizer que eu tenha saído "vitoriosa" do embate. O presente texto não pretende ser uma narrativa heroica de como a autora conseguiu provocar a acolhida triunfal da sabedoria das ciências sociais. Antes, se constitui numa tentativa de explorar a produtividade da minha própria perplexidade para recolocar uma pergunta que deve permanecer presente nas nossas investigações: quais são os efeitos de nossa prática acadêmica? Lembrando que o caminho em direção a uma sociedade mais justa e igualitária é longo, minha experiência sugere que, em determinadas situações, pode ser producente refletir antes de passar julgamento, imaginar a possibilidade de alianças estratégicas antes de provocar inimizades. Antes de tudo, emerge a convicção de que "avanços" (sociais ou científicos) não se realizam sem um paciencioso trabalho de mediação, com a concomitante transformação de todos os atores envolvidos.

\section{Referências}

ABI-RACHED, Joelle; ROSE, Nikolas. "The birth of the neuromolecular gaze". History of the human sciences, London, v. 23, n. 1, p. 11-36, 2010.

ACADEMIA BRASILEIRA DE CIÊNCIAS. Sumário das conclusões e recomendações do, de trabalho sobre Educação Infantil. Disponível em: http://todospelaeducacaoitajai.ning.com/forum/topics/ sumario-das-conclusoes-e. Acesso em: 26/4/201 1.

AZIZE, Rogerio Lopes. "O cérebro como órgão pessoal: uma antropologia de discursos Neurocientíficos". Trabalho, Educação, Saúde, Rio de Janeiro, v. 8 n. 3, p. 563-574, 2010.

BEHAGUE, Dominique. "Psychiatry, bio-epistemes and the making of adolescence in southern Brazil”. História, Ciência, Saúde-Manguinhos, Rio de Janeiro, v. 23, n. 1, p. 131-154, março, 2016.

BELLACASA, Maria Puig. "Matters of care in technoscience: Assembling neglected things." Social Studies of Science. v. 41 , n. 1 p. 85-106, dez. 2010.

BROER, Tineke; PICKERSGILL, Martyn. "Targeting brains, producing responsibilities: The use of neuroscience within British social policy". Social Science and Medicine, Boston, v. 132, p. 54-61, mar. 2015.

BRUER, John. The myth of the first three years: a new understanding of early brain development and lifelong learning. New York: Free Press, 1999.

DIDONET, Vital (Org.). Plano Nacional da Primeira Infância. Brasília: Rede Nacional Primeira Infância, 2010.

DUMIT, Joseph. "Is it me or my brain? Depression and neuroscientific facts". Journal of Medical Humanities, Denver, v. 24, n. 1/2, p.36-47, jun. 2003.

DUMIT, Joseph. Picturing Personhood: Brain Scans and Biomedical Identity. Princeton, NJ: Princeton University Press, 2004.

FASSIN, Didier. "Why ethnography matters: Anthropology and its publics". Cultural Anthropology, Washington D.C., v. 28, n. 4, p. 621-646, 2013.

FERNANDES, Camila. Figuras da causação: Sexualidade feminina, reprodução e situações no discurso popular e nas políticas do Estado. 2017. Tese (Doutorado em Antropologia), Programa de Pós-Graduação em Antropologia Social, Museu Nacional, UFRJ, Rio de Janeiro, Brasil. 
FONSECA Claudia. Família, fofoca e honra. Porto Alegre: Editora da UFRGS, 2000.

FONSECA, Claudia, "Que ética? Que ciência? Que sociedade?" In: FLEISCHER, Soraya e SCHUCH, Patrice (Orgs.). Ética e regulamentação na pesquisa antropológica. Brasília/UnB, Letras Livres, 2010. p. 39-70.

FONSECA, Claudia. "Tecnologias globais de moralidade materna: as interseções entre ciência e política em programas "alternativos" de educação para a primeira infância". In: FONSECA, Claudia; ROHDEN, Fabiola; MACHADO, Paula S. (Orgs). Ciências na Vida: Antropologia da ciência em perspectiva. São Paulo: Editora Terceiro Nome, 2012.

FONSECA, Claudia. Caminhos da adoção. São Paulo: Editora Cortez, 1995.

FONSECA, Claudia; SCHUCH, Patrice (Orgs.). Políticas de proteção à infância: um olhar antropológico. Porto Alegre: Editora da UFRGS, 2009.

GRAHAM, Allen. Early Intervention: The Next Steps, An Independent Report to Her Majesty's Government. London: Cabinet Office, 2011.

HARAWAY Donna. Modest_Witness@Second_Millennium. FemaleMan (C)_Meets_OncoMouse ${ }^{\mathrm{TM}}$ : Feminism and Technoscience. New York: Routledge, 1997.

HIRATA, Helena; GUIMARÃES, Nadya Araujo (orgs.). Cuidado e cuidadoras: as várias faces do trabalho do care. São Paulo: Editora Atalas, 2012.

HSU, Christine. "Chilling Brain Scans Show the Impact of a Mother's Love on a Child's Brain Size". Medical Daily, 29 outubro, 2012. Disponível em: https://www.medicaldaily.com/chilling-brain-scansshow-impact-mothers-love-childs-brain-size-243328. Acesso em: 29/12/2017.

IBGE. Síntese de indicadores sociais: Uma análise das condições de vida da população brasileira. Estudos e pesquisa, Informação demográfica e socioeconômica, número 32. Brasília, 2013.

JASANOFF, Sheila (Org). States of knowledge: the co-production of science and social order. New York, Routledge, 2004.

LATOUR, Bruno. Reassembling the social: An introduction to actor-network-theory. Oxford: Oxford University Press, 2005.

LEWIS Paul; BOSELEY, Sarah. "Iain Duncan Smith 'distorted' research on childhood neglect and brain size". The Guardian, 9 abril, 2010. Disponível em: https://www.theguardian.com/politics/2010/apr/ 09/iain-duncan-smith-childrens-brains. Acesso em: 29/12/2017.

LITTLEFIELD, Melissa; JOHNSON, Jenell. The neuroscientific turn: transdisciplinarity in the age of the brain. Ann Arbor: University of Michigan, 2012.

LUGON Ricardo; FREITAS, Claudia Rodrigues. "Olhando para o cérebro dos aprendentes: Reflexões para um desencantamento imagético na educação". Revista Culturas Psi/Psy Cultures, Buenos Aires, n. 6, p.12-27, mar. 2016.

MACHADO, Helena. "Genética e suspeição criminal: reconfigurações atuais de coprodução entre ciência, ordem social e controlo". In: FONSECA, Claudia; MACHADO, Helena (Orgs.). Ciencia, identificação e tecnologias de governo. Porto Alegre: Editora da UFRGS, 2015.

MARIANO, Fernanda Neísa; ROSSETTI-FERREIRA, Maria Clotilde. "Que perfil da família biológica e adotante, e da criança adotada revelam os processos judiciais?". Psicologia, Reflexão, Critica, Porto Alegre, v. 21, n. 1, p. 11-19, 2008.

MCCAIN, Margaret; MUSTARD, Fraser. Early Years Study: final report. Toronto, Publications Ontario, 1999.

MOL, Annemarie. The logic of care: Health and the problem of patient choice. New York: Routledge, 2008.

MORAES, José Carlos Sturza de. “Um Encontro a três mães: Mas três não é demais?". In: PAULY, Lodi; MORAES, José Carlos Sturzade; SANTOS, Karine dos (orgs.). Boas Práticas Garantindo o Direito à Convivência Familiar e Comunitária de Crianças e Adolescentes no RS. São Leopoldo, RS: Amencar e Secretaria de Direitos Humanos da Presidência da República, 2012. 
O'CONNOR, Cliodhna; JOFFE, Helene. "Media representations of early human development: Protecting, feeding and loving the developing brain". Social Science \& Medicine, London, v. 97, p. 297-306, nov. 2013.

O'CONNOR, Cliodhna; REES, Geraint; JOFFE, Helene; "Neuroscience in the Public Sphere". Neuron, Washington DC, v.74, p. 220-226, abr. 2012.

PERRY, Bruce. "Childhood experience and the expression of genetic potential: what childhood neglect tells us about nature and nurture". Brain and Mind, Dordrecht (Holanda), v. 3, p. 79-100, abr. 2002.

PERRY, Bruce; POLLARD, Ronnie. Altered brain development following global neglect in early childhood. Society for Neuroscience: Proceedings from Annual Meeting, New Orleans, 1997. Disponível em: https://childtrauma.org/wp-content/uploads/2013/12/PerryPollard_SocNeuro.pdf. Acesso em: 29/12/ 2017.

RIJCKE, Sarah; BEAULIEU, Anne. "Essay Review: Taking a Good Look at Why Scientific Images Don't Speak for Themselves". Theory \& Psychology, Groningen, v. 17. p. 733-742, out. 2007.

ROSE, Nikolas. "'Screen and intervene': governing risky brains". History of the Human Sciences, London, v. 23, n. 1, p. 79-105, março 2015.

ROSE, Nikolas. Neuro: the new brain sciences and the management of the mind. Princeton: Princeton University Press, 2013.

SANTIAGO DECLARATION. 2007. Disponível em: http://www.santiagodeclaration.org. Acesso em: 26/ $4 / 2011$.

SCHLEIM, Stephan. "Critical neuroscience - or critical science? A perspective on the perceived normative significance of neuroscience". Frontiers in Human Neuroscience, Berlin, v. 86, p. 1-6, mai. 2014.

SCHNEIDER, Dorith. 1985. "Alunos excepcionais': um estudo de caso de desvio". In: VELHO, Gilberto (Org.). Desvio e divergência: uma crítica da patologia social. Rio de Janeiro: Zahar, 1985.

STERN, Alexandra. Eugenic nation: faults and frontiers of better breeding in Modern America. Berkeley: University of California Press, 2005.

VALENTE, Janete. As relações de cuidado e de proteção no Serviço de Acolhimento em Família Acolhedora. 2013. Tese (Doutorado em Serviço Social) - Programa de Pós-graduação em Serviço Social, Pontifícia Universidade Católica de São Paulo, São Paulo, Brasil.

WILLIAMS, Zoe. 2014. "Is misused neuroscience defining early years and child protection policy?". The Guardian, London, 26 abr., 2014. (https://www.theguardian.com/education/2014/apr/26/ misused-neuroscience-defining-child-protection-policy. Acesso em: 12/8/2017).

YOUNG, Mary Eming, Early Child Development: From Measurement to Action: A priority for Growth and Equity. Washington: World Bank, 2007

ZIRBEL, Ilze. Uma teoria política feminista do cuidado. 2016. Tese (Doutorado em Filosofia), Programa de Pós-Graduação em Filosofia, UFSC, Florianópolis, Brasil.

Claudia Fonseca (claudialwfonseca@gmail.com) é professora do Programa de PósGraduação em Antropologia Social da Universidade Federal do Rio Grande do Sul (Brasil). Seus interesses de pesquisa incluem parentesco, gênero, ciência e direito, com ênfase particular nos temas de direitos humanos e tecnologias de governo. Além de recentes artigos em Horizontes Antropológicos, Mana, Cadernos Pagu, Política e Trabalho e Revista Reia, é autora do livro Parentesco, tecnologia e lei na era do DNA, e co-organizadora (com Denise Jardim) de Promessas e incertezas da ciência: Perspectivas antropológicas sobre saúde, cuidado e controle.

\section{COMO CITAR ESSE ARTIGO DE ACORDO COM AS NORMAS DA REVISTA}

FONSECA, Claudia Lee Williams. "Crianças, seus cérebros... e além: Reflexões em torno de uma ética feminista de pesquisa". Revista Estudos Feministas, Florianópolis, v. 27, n. 2, e56169, 2019. 


\section{CONTRIBUIÇÃO DE AUTORIA}

Não se aplica.

\section{FINANCIAMENTO}

\section{CNPq}

CONSENTIMENTO DE USO DE IMAGEM

Não se aplica.

\section{APROVAÇÃO DE COMITÊ DE ÉTICA EM PESQUISA}

Não se aplica.

\section{CONFLITO DE INTERESSES}

Não se aplica.

\section{LICENÇA DE USO}

Este artigo está licenciado sob a Licença Creative Commons CC-BY Internacional. Com essa licença você pode compartilhar, adaptar, criar para qualquer fim, desde que atribua a autoria da obra.

\section{HISTÓRICO}

Recebido em 03/04/2018

Reapresentado em 19/08/2018

Aprovado em 24/08/2018 